\title{
Teaching Design and Thinking of General Courses of Chinese Department Based on OBE (Outcomes- based Education) Concept
}

\author{
Chong Wang ${ }^{1, *}$ \\ ${ }^{I}$ School of Literature and Journalism, Inner Mongolia University, Hohhot, Inner Mongolia 010070, China \\ *Corresponding author. Email: wangchong1980@126.com
}

\begin{abstract}
Under the OBE (outcomes-based education) concept, the ultimate goal of education is the learning achievement of learners. Therefore, focusing on the exertion and training of students' autonomy and innovation has become an important link in teaching activities. Applying the OBE concept to the teaching reform experiment of the "Chinese and Ancient Chinese Culture" course, based on traditional teaching methods, combining mixed and experiential teaching methods, and using the " $3+2$ " comprehensive assessment model to comprehensively evaluate students, can not only find new breakthroughs for the teaching of "Chinese and Ancient Culture of China", but also provide a certain reference for the teaching reform of other related courses in the Chinese Department.
\end{abstract}

Keywords: OBE (outcomes-based education) concept, Chinese and Ancient Culture of China, Curriculum reform, General education, Teaching design.

\section{INTRODUCTION}

Outcomes-based education was first proposed by William Spady (1981), the "father of outcome-based education" in the United States. In his book "OutputBased Education: Controversies and Answers", he defines OBE as "clearly organizing and focusing on the education system to make it centered on ensuring that students gain substantial success in their future lives." [1] From this point of view, Spady believes that the core and ultimate goal of education is the learning outcomes of learners. In the 1980s and 1990s, Australia, the United States and other countries have infused the concept of outcomeoriented education into basic education and achieved remarkable results. In recent years, many colleges and universities in China have adopted the OBE concept for teaching reform. The application in polytechnic is particularly extensive, which is of great benefit to the cultivation of comprehensive talents in university education.

*Project: Discussion on the teaching mode of general education courses in colleges and universities under the construction of "Double First Class" in the context of OBE concept.

Project No.: NDJG-20-04
Many courses offered by the Chinese Department emphasize theory over practice and application. However, "College Chinese", "Chinese and Ancient Culture of China" and other Chinese general education courses are faced with students from other colleges except the College of Liberal Arts. This also means that the teaching content and methods of the general courses of the Chinese Department cannot adopt the same model as that of the major. The fruitful results of the OBE concept in the reform of science and engineering courses should also be absorbed and used for reference by the humanities and social sciences courses. This research selects "Chinese and Ancient Chinese Culture" as a general education elective course as a reform pilot, combines the author's years of teaching experience and uses OBE teaching concepts to carry out the teaching reform of this general elective course, striving to provide a certain reference in the research and practice for the curriculum reform of the Chinese Department and the teaching reform of general education elective courses. 


\section{TAKING TRADITIONAL TEACHING MODEL AS THE BASIS}

Students are relatively free in the choice of general education elective courses. Students can choose courses according to their preferences, interests, needs, etc. Therefore, every student who participates in the general elective course "Chinese and Ancient Culture of China" this semester has different demands. Then, how to achieve the goal of teaching reform while ensuring the quality of teaching is very important. In accordance with the curriculum goal of "Chinese and Ancient Culture of China", the teaching content is reversely designed. At the same time, paying attention to the sense of hierarchy and design of the teaching content, and paying attention to the adaptability, popularity and practicability of the teaching content to students of different majors are the principles and core of this curriculum teaching reform practice.

There are a total of 11 weeks for general education elective courses. This course is divided into two modules. The first module is 5 weeks in total, and the second module is 6 weeks. The teaching content of the first module is mainly based on the basic knowledge involved in the course. Only by letting students know enough about the teaching content of the course can they lay a good foundation for subsequent participation. Therefore, the first module adopts the traditional "teacher lecture + student interaction" model.

This course mainly focuses on traditional elementary school and ancient document training. The former mainly includes the teaching of ancient Chinese knowledge such as characters, phonology, and exegesis. It can be coupled with the original classics such as "The Book of Songs", "Zuo Zhuan", "Shih Chi" and "Han Shu". And it is necessary to set up some comprehensive general theory courses appropriately. Part of the content requires students to directly use the original (unpunctuated) classics, histories, subtitles, and collections of classics, such as "Annotation to the Thirteen Classics", etc., to train students to learn traditional characters and read punctuation. This part of knowledge is more basic, mainly aiming to "guide students to understand the classics, know allusions, understand the historical facts, and understand the truth through the analysis of the humanistic connotation of classical Chinese works." [2] This part of content is highly professional, so it is mainly taught by teachers independently. Of course, the content involved in this part is also very extensive, and teachers can naturally find enough opportunities to interact with students.
For example, when teaching knowledge of ancient characters, students can practice writing ancient characters by themselves. When teaching phonology related knowledge, they can combine local dialects and modern Chinese phonetics to teach. Students can also use the hometown dialect in the classroom to read paragraphs and other forms, which can not only enhance the interaction between students and teachers, but also enhance students' understanding of phonetic knowledge.

\section{COMBINATION OF BLENDED PLUS EXPERIENTIAL TEACHING METHODS}

The second module of the "Chinese and Ancient Culture of China" course has a total of 6 weeks. The OBE concept will be used to arrange the courses. This part mainly adopts the "student lecture + teacher comment" model. Among them, 2 class hours are used for blended teaching and 4 class hours are used for experiential teaching.

The first is to adopt a blended teaching model. Blended teaching methods present diversified characteristics in terms of teaching content, teaching media and student interaction. "Blending learning emphasizes the trinity of online learning, classroom learning, and group collaboration."[3] The blended teaching is expected to practice 2 class hours and adopt two forms. In the first class hour, students are given a topic selection in advance. Students are required to review and study the selected topics in one week, and conduct random roll calls and unscripted answers to examine students in class. On the one hand, it can check the completion of the students' homework. On the other hand, it can exercise the students' ability to speak out of line. In the second class, the teacher temporarily selects the topic in class, and adopts the model of unleaded group discussion. Students are randomly divided into groups to give students enough time to discuss the topic. "In the practice of group teaching, the collision of different viewpoints has cultivated students' ability to analyze problems, make judgments and make critical thinking. Collaboration, disagreement, speculation, appraisal, and reflection among students run through, protecting the development of personality, and also inspiring active thinking and creativity. "[4] Teachers can also record the participation of each student in the group during the discussion, and finally each group selects a student representative to make a summary answer.

Secondly, the experiential teaching model is adopted to conduct independent teaching training for 
students. Due to the large number of students, experiential teaching can be conducted in 4 class hours. Students are accustomed to the traditional teaching model, and they are somewhat afraid of "exchanging roles" with teachers, but experiential teaching can well stimulate students' independent learning ability, language expression ability, and improvisational ability. The purpose of the general education elective courses offered by the school is to, on the one hand, hope that students can learn more about other majors while studying the courses of this major. On the other hand, it is hoped that students can find their own points of interest while learning more knowledge. General education elective courses are generally opened from $7 \mathrm{pm}$ to $10 \mathrm{pm}$. Many students are very tired in the day and night. Therefore, in the practice of experiential teaching, teachers should give a reasonable range of topics and propose reasonable requirements, which is to not only achieve the goals and expectations of the curriculum reform, but also try not to cause unnecessary trouble and excessive pressure to the students.

This course is based on traditional Chinese culture, so students have great autonomy in selecting the content of the course. Teachers can choose some topics for students, such as Chinese and ancient Chinese surnames, rule system, marriage system, book system, etiquette system, school education, etc. [5] Of course, it would be better if students can combine the relevant knowledge of Chinese and ancient culture of China with their major. Due to the large number of general elective courses, this part of the content requires a strict time limit, that is, students must explain clearly the topics they have prepared within a limited number of minutes, and use the form of lectures instead of lectures or recitations. They can use the blackboard and interact with other students. After each student has finished teaching, the teacher should make a brief evaluation and give reasonable suggestions. The students can also comment on each other, and the teacher will give the final score.

\section{USING "3 PLUS 2" ASSESSMENT MODEL TO CARRY OUT COMPREHENSIVE EVALUATION}

In order to better evaluate the learning effects of students and the practical effects of teaching reform, the "3+2" assessment model is adopted when the students' total score is given. The three processes of "learning attitude, classroom discussion, self-teaching content design and teaching effect" are included in the evaluation scope, and at the same time, the final grades of the course are comprehensively given to the students in combination with the final exam results, attendance, and compliance with classroom discipline.

The traditional scoring method adopts "threeseven", that is, attendance and mid-term exam scores account for $30 \%$, and final scores account for $70 \%$ of the total score. However, the evaluation system led by the OBE concept requires a comprehensive and overall approach, so the scoring method can be changed to "five-five". The learning attitude runs through the whole course. Therefore, in the evaluation, this part can be comprehensively scored based on the interaction of the traditional teaching model + blended teaching practice and the preparation of the student's independent lecture part. Secondly, in blended teaching, the first mode mainly examines students' importance to the curriculum, information retrieval ability and autonomous learning ability. This part gives students one week to prepare, so they can give scores ranging from 5 to 10 based on the students' speech and their understanding of the topic. The second model, that is, the non-leader group model, examines the students' cooperative ability, speculative ability and students' ability to summarize and present. According to the teacher's observation during the student discussion and the final speech of the group representative, the teachers give scores ranging from 5 to 10 points. In the process of discussion, it is inevitable that some students may appear to be "slack" and other opportunistic situations. Teachers can ask questions after the student representatives have summed up and ask group members to assist in answering. Other groups of students can also ask questions to them, and even conduct small debates to effectively mobilize students' enthusiasm. The third part of the score is mainly for scoring students' self-taught courses. This part can give scores ranging from 10-25 points. Students' self-taught can evaluate the content in terms of correctness, completeness, novelty, etc., and evaluate students' "typhoon" in terms of behaviour, blackboard design and interaction with other students. The student's teaching must be carried out off-line, and the teacher can make a reasonable evaluation and put forward comments on the student's lecture before the score is given.

In addition to the above three parts, there are other mandatory requirements for school education, such as attendance and final exams. Classroom discipline scores such as attendance should be reduced from the original $10 \%$ to $5 \%$. On the one hand, blended and experiential teaching require students' interaction and participation, which greatly 
reduces the probability of students skipping classes, missing classes, and absenteeism. On the other hand, teachers can randomly roll names and interact with students during the first 5 weeks of teaching practice in the first module, which can also effectively reduce the phenomenon of students skipping classes. Of course, it is hoped to cultivate students who respect the classroom and teachers. Absence from work for no reason is also the basic line and principle of students.

Finally, the proportion of final exam scores should decrease from $70 \%$ to $50 \%$. The final exam adopts the school's unified closed-book test requirements. The closed-book test questions are mainly based on basic knowledge questions and open-type test questions. Basic knowledge should account for $20 \%$ of the whole paper and open-type test questions account for $30 \%$. Basic knowledge questions are the basic knowledge of the subject taught in the classroom. This part of knowledge is mainly explained in the first 5 weeks, and students should be familiar with it. The open test questions will test the students' comprehensive application ability of the 11 weeks. This is also the essence of the OBE concept, that is, the emphasis on the cultivation of students' application ability and the investigation of students' final learning effects. On the whole, the final exam paper will not exceed the outline, nor will it cause too much study pressure on students.

Adopting the " $3+2$ " assessment model, teachers can get a more comprehensive and detailed understanding of the students' performance in this course, and can also give fair and reasonable results. At the same time, for this course reform, the " $3+2 "$ assessment model also comprehensively tracks and records the entire course of curriculum reform based on the OBE concept. The most important thing is that under such an assessment model, teachers can find breakthroughs in improving teaching quality and improving teaching content and effects. For students, the OBE concept behind the "3+2" assessment model also affects them invisibly. "Under the OBE concept, educators must have a clear idea of the ability and level that students should reach when they graduate, and then design appropriate education structure to ensure that students achieve their desired goals."[6] It is believed that after the end of the course of this semester, students' autonomous learning ability will be greatly improved. At the same time, it will also greatly promote students' self-confidence, students' search for future directions and research interests.

\section{CONCLUSION}

As a teaching concept and reform model with great operability and significant effects explored in teaching practice, OBE has adapted to the country's needs for cultivating comprehensive talents and improving the quality of quality education at the macro level. At the micro level, it also meets the needs for teachers to improve classroom teaching and students to improve their independent learning ability. From this point of view, the OBE concept is completely compatible with the cultivation of innovative and comprehensive talents in university education. "Chinese and Ancient Culture of China" as a subject to popularize traditional cultural knowledge and enhance students' ability to appreciate traditional culture, applying the OBE concept to the reform and design of this course can not only improve the teaching quality of this course, but also provide a certain reference for the teaching reform of other related courses in the Chinese Department.

\section{AUTHORS' CONTRIBUTIONS} Wang.

This paper is independently completed by Chong

\section{REFERENCES}

[1] Zhu Zhengwei, Information Talents Under the OBE Concept "One-body Four-wing Characteristic Training Program Collection" [M]. Chengdu: University of Electronic Science and Technology of China Press, 2017 (4): 4. (in Chinese)

[2] Yao Lixia, Zhang Shengguang, Wang Jinping, Construction and Practice of Ancient Chinese Course Based on OBE Education Concept [J]. The Theory and Practice of Innovation and Entrepreneurship, 2020 (2): 30. (in Chinese)

[3] He Kekang, Viewing the New Development of Educational Technology Theory from Blending Learning (Part 1) [J]. E-education Research, 2004 (3): 2. (in Chinese)

[4] Cheng Chunling, Zheng Silu, Yang Jian, Reform and Practice of OBE Fused Course Teaching in Context of New Engineering Education [J]. Computer Era, 2020 (8): 119. (in Chinese)

[5] Cheng Yao, Exploration on the Ideological and Political Construction of Ancient Chinese 
Course [J]. Survey of Education, 2020, 9(21): 25. (in Chinese)

[6] Xia Xumei, Thoughts on Ideological and Political Teaching of Courses Based on OBE Concept [J]. Education and Teaching Forum, 2020 (8): 40. (in Chinese) 